\title{
A Case of Bilateral Severe Sensorineural Hearing Loss Associated with Kawasaki Disease
}

\author{
Masakazu Hamamoto, Yukiyoshi Hyo, Hiroki Tanaka, Toshihiro Tachi, \\ Norimasa Morita, Hisaki Fukushima and Tamotsu Harada
}

\begin{abstract}
Kawasaki disease (KD) is an idiopathic systemic vasculitis common in infants and children that affects predominantly small and medium-sized extraparenchymal muscular arteries. KD manifests various clinical symptoms, of which coronary aneurysms are the most important complication. However, the association of sensorineural hearing loss with KD is rare. A 7-year-old girl with KD was referred to our department with a chief complaint of hearing loss. In her hearing test, she showed a high degree of bilateral sensorineural hearing loss. Although the patient was treated with steroid pulse therapy (methylprednisolone), her hearing level deteriorated. Two weeks after steroid therapy, a slight improvement was seen. Thereafter, the patient started to use hearing aids. About one year has elapsed since the onset of hearing loss, but her hearing level has not improved.
\end{abstract}

Keywords : sensorineural hearing loss, Kawasaki disease, vasculitis, steroid pulse therapy

\section{References}

1）川崎富作：指趾の特異的落屑を伴う小児の急性熱性皮膚粘 膜淋巴腺症候群一自験例 50 例の臨床的観察一. アレルギー 16: 178-222, 1967.

2）屋代真弓, 上原里程, 中村好一, 他 : 第 21 回川崎病全国調 查成績. 小児診療 75: 507-523, 2012.

3）石渡隆寛：川崎病治療の最近の知見. 小児臨 63：381-390, 2010.

4）高 永煥：川崎病一原因不明の小児特有の血管炎症候群, その過去，現在，未来一。金沢医大誌 30: 1-5, 2005.

5) Poon LK, Lun KS, Ng YM, et al. : Facial nerve palsy and Kawasaki disease. Hong Kong Med J 6: 224-226, 2000.

6）天津治子，小田隆造，播磨良一，他：感音難聴を呈した川 崎病既往児の 2 症例. 小児耳鼻 8: 28-30, 1987.

7）高橋亮一，鳥越克己，原錬太郎，他：川崎病のおける聴力 障害について。 日小児会誌 90: 198, 1986.

8) Sundel RP, Cleveland SS, Beiser AS, et al. : Audiologic profiles of children with Kawasaki disease. Am J Otol 13: 512-515, 1992.

9) Magalhães CM, Magalhães Alves NR, Oliveira KM, et al. : Sensorineural Hearing Loss: an underdiagnosed complication of Kawasaki disease. J Clin Rheumatol 16: 322-325, 2010.

10) Knott PD, Orloff LA, Harris JP, et al. : Sensorineural hearing loss and Kawasaki disease: a prospective study. Am J Otolaryngol 22: 343-348, 2001.

11）野々田亨, 永井崇雄, 大西正純, 他 : 川崎病の経過中に突 発性難聴をきたした 1 例。小児臨 36：1259-1262, 1983.

12）三浦 洋，佐々木美帆，萩原温久，他：パルス療法著効の 難聴を合併した MCLSの 1 例. 小児臨 39: 2180-2184, 1986.

13）鈴木啓之，柳川敏彦，紀平省悟，他：川崎病に聴力障害を 合併した 2 例. 小児臨 41：845-850, 1988 。

14）高木みどり, 土屋邦子, 中島文明, 他 : 川崎病の急性期経 過中に難聴を来たした 2 例。小児臨 41：2456-2460, 1988.
15）中山京子，野田英作，山家宏宣，他：一過性聴力障害を合 併した川崎病の 1 例. 和歌山医 54: 143, 2003.

16）佐藤宏紀, 柏村正明, 千田英二, 他：川崎病急性期に両感 音難聴を認めた 1 例. Otol Jpn 15: 397, 2005.

17）松田文子, 木内 英, 菅谷明則, 他 : 難治性川崎病に合併 した高度難聴の 1例。日小児会誌 109: 834-838, 2005.

18）荒新 修, 安村純子, 林 知宏, 他: 感音性難聴を合併し た川崎病の 1 例. 日小児会誌 112：1700-1706, 2008.

19）中島恭子, 長井今日子, 古屋信彦: 川崎病に両側高度感音 難聴を合併した 1 例. Otol Jpn 18: 571, 2008.

20）市川朝也, 籠谷領二, 松中絵美, 他 : 不全型川崎病に合併 した急性感音性難聴の 1 例。小児耳鼻 32：222, 2011.

21）大西徳子, 萩原優子, 谷口裕章, 他：感音性難聴を合併し た川崎病の 1 例. Prog Med 31：1671-1674, 2011.

22）野村恭也：総括研究報告. 厚生省特定疾患急性高度感音難 聴調查研究班昭和 59 年度研究業績報告書. 1-3 頁, 1984 .

23) Sundel RP, Newburger JW, McGill T, et al. : Sensorineural hearing loss associated with Kawasaki disease. J Pediatr 117: 371-377, 1990 .

24) Gong GW, McCrindle BW, Ching JC, et al. : Arthritis presenting during the acute phase of Kawasaki disease. J Pediatr 148: 800-805, 2006.

25）武山 彩, 大原信一郎, 高野 恵, 他 : 免疫グロブリン療 法不応の川崎病で回復期に関節症状を呈した 3 例. 小児科 50: 2083-2089, 2009.

26）今井裕一，本間 卓，菅原 保，他：感音難聴を合併した 結節性多発動脈炎の 1 例 : Cogan 症候群の非典型例. 内科 70: 593-595, 1992.

27) Gussen P : Polyarteritis nodosa and deafness. A human temporal bone study. Arch Otorhinolaryngol 217: 263-271, 1977.

28) Yoon TH, Paparella MM and Schachern PA : Systemic vasculitis: a temporal bone histopathologic study. Laryngoscope 99 : 600-609, 1989.

29）藤川 敏：川崎病と血管炎. 小児診療 60：945-950, 1997. 

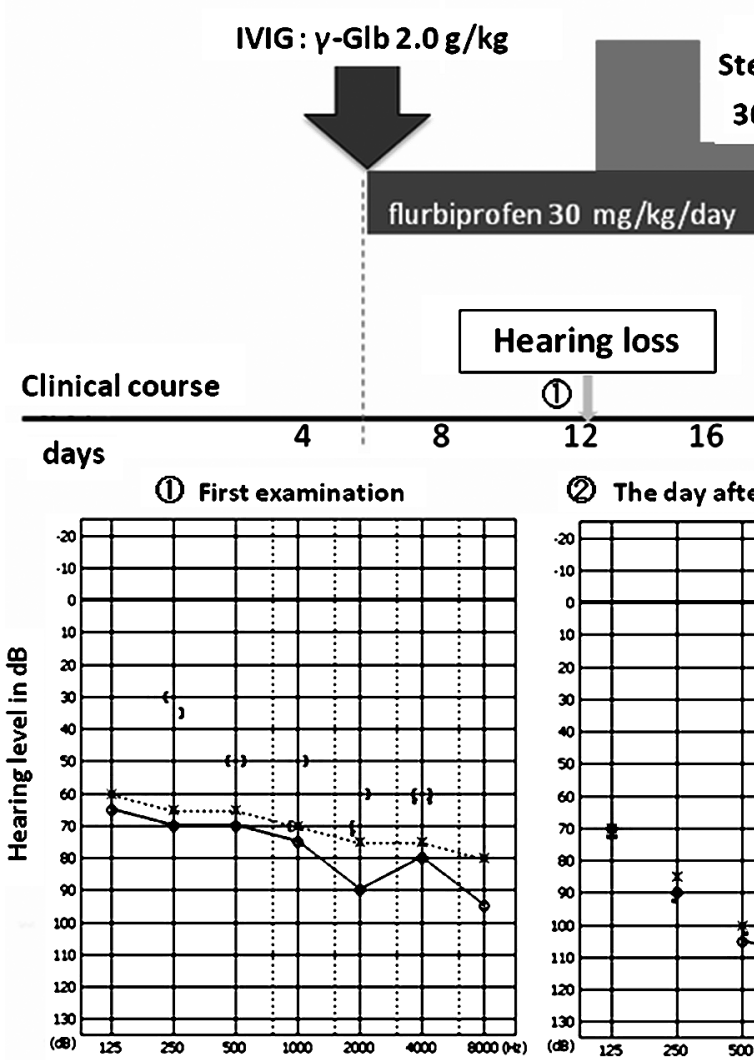

\section{Hearing loss} (1)
IVIG: Intravenous immunoglobulin mPSL: methylprednisolone

PSL: prednisolone

$30 \rightarrow 1 \rightarrow 0.5 \mathrm{mg} / \mathrm{kg} / \mathrm{day}$

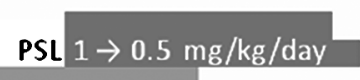

aspirin $30 \rightarrow 5 \mathrm{mg} / \mathrm{kg} / \mathrm{day}$
Hip pain, Thigh pain
Hip arthritis with KD

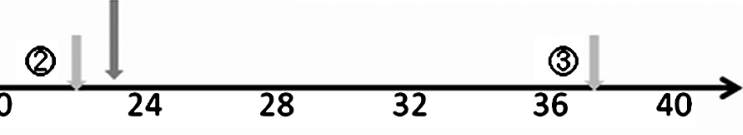

(8) The day after steroid pulse therapy

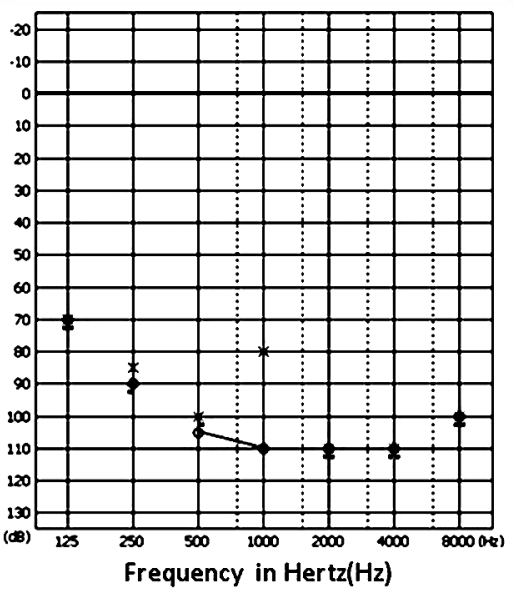

(3) Two weeks after steroid pulse therapy

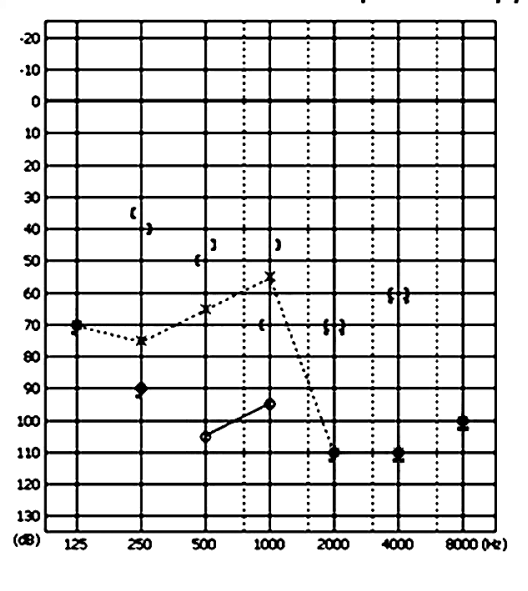

Clinical course

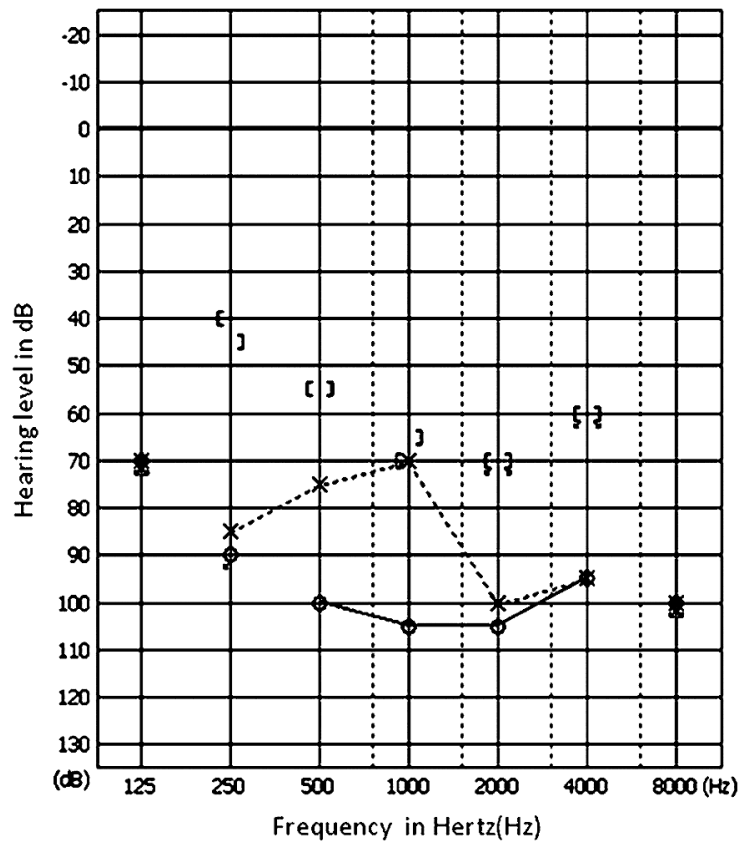

Audiogram (About one year after the onset) 